\title{
Use of "Inside-Out" Technique for Direct Visualization of a Vacuum Vertically Unstable Intervertebral Disc During Routine Lumbar Endoscopic Transforaminal Decompression-A Correlative Study of Clinical Outcomes and the Prognostic Value of Lumbar Radiographs
}

\author{
KAI-UWE LEWANDROWSKI, MD, ${ }^{1,2}$ JORGE FELIPE RAMÍREZ LEÓN, MD, ${ }^{3}$ ANTHONY YEUNG, MD ${ }^{4,5}$ \\ ${ }^{1}$ Center for Advanced Spine Care of Southern Arizona, Tucson, Arizona, ${ }^{2}$ Surgical Institute of Tucson, Tucson, Arizona, ${ }^{3}$ Spine Surgery Program, Universidad El \\ Bosque, Bogotá, Colombia, ${ }^{4}$ Department of Neurosurgery, University of New Mexico School of Medicine, Albuquerque, New Mexico, ${ }^{5}$ Desert Institute for Spine \\ Care, Phoenix, Arizona
}

\begin{abstract}
Background: The purpose of this study was to record the frequency of lumbar intervertebral disc vacuum phenomenon on routine lumbar plain films taken prior to transforaminal endoscopic decompression surgery for sciatica-type leg and back pain and to correlate it with visualized intradiscal pathology and clinical outcomes.

Methods: A prospective case series study of 200 consecutive patients with an average mean follow-up of 41.85 months who underwent lumbar endoscopic transforaminal decompression at 236 lumbar levels was conducted. The sensitivity, specificity, and accuracy of vacuum phenomenon on preoperative x-ray to predict the presence of an empty vacuum disc found during transforaminal microdiscectomy using the "inside-out" approach were calculated using the YESS $^{\text {TM }}$ technique. Clinical outcomes were assessed by both Macnab criteria and visual analog score (VAS) reduction.

Results: Of the 200 patients evaluated, $124(62 \%)$ were deemed to have a vacuum disc on intraoperative probing using the "inside-out" technique. During needle insertion the more severely degenerative discs are met with negative pressures manifested by an air discogram. According to Macnab criteria, all patients who also had extruded disc herniations had excellent results ( 8 of 200), with the mean VAS decreasing from $6.1 \pm 2.6$ preoperatively to $1.9 \pm 1.4$ at the final follow-up $(P<.01)$. This indicates a more severely degenerative disc causing nonspecific back pain due to lack of anterior column support from the intervertebral disc, accentuating foraminal stenosis. Patients with contained disc herniations (62 of 200) had excellent and good results $82.2 \%$ of the time. The mean VAS decreased from $6.9 \pm 1.7$ preoperatively to $2.2 \pm 1.1$ at final follow-up $(P<.01)$. This identifies the disc as a contributing factor in low back pain. It can also identify the disc and annulus in combination with foraminal stenosis as a contributing factor. In the spinal stenosis group (130 of 200), 81.5\% of patients had excellent to good results, and the mean VAS decreased from $6.3 \pm 1.5$ preoperatively to $2.1 \pm 1.2$ at final follow-up $(P<.01)$. An analysis of lumbar $\mathrm{x}$-ray vacuum phenomenon in patients with visualized vacuum disc showed true-positive (35 patients) and false-negative ( 89 patients), compared with an $\mathrm{x}$-ray negative grading in patients without intraoperatively visualized vacuum disc of false-positive (2 patients); and true-negative (74 patients); this allowed for calculation of sensitivity $(28.2 \%)$, specificity $(97.4 \%)$, and positive predictive value $(94.6 \%)$ of preoperative diagnostic $\mathrm{x}$-ray in relation to intraoperatively visualized presence of the vacuum disc during subsequent endoscopic decompression surgery. Direct endoscopic visualization of the inside of the vacuum disc revealed longitudinal fissuring of the intervertebral disc as the most common finding in 77 of the 124 patients $(62.1 \%)$ with a vacuum disc. Cavitation with delamination was the second most common observation (21 patients). Fair outcomes were associated with cavitation and delamination of the intervertebral disc from the endplates $(P<.0001)$.

Conclusions: A vacuum phenomenon seen on lumbar x-rays is highly specific for a source of one component that is actually a multiple source of nonspecific common back pain. A vacuum disc being found during "inside-out" transforaminal discectomy actually encompasses the disc, annulus, and foraminal stenosis as a multifactorial source of nonspecific common back pain. Further studies of better prognosticators of failed endoscopic transforaminal discectomy are required and are underway by the coauthors.
\end{abstract}

Minimally Invasive Surgery

Keywords: disc vacuum phenomenon, lumbar endoscopic transforaminal decompression 


\section{INTRODUCTION}

A vacuum intervertebral disc is frequently encountered during routine lumbar transforaminal endoscopic decompression for sciatica-type low back and leg pain. Its impact on surgical outcomes has recently been reported. ${ }^{1-3}$ Surgeons expect it, particularly when a vacuum phenomenon is noted on preoperative radiographs of the lumbar spine., ${ }^{4,5}$ Degeneration leading to structural changes of the collagen composition within the human lumbar disc has been found to commence as early as age 18 years and progresses with increasing age. ${ }^{6}$ The significance of this process regarding the prognosis of clinical intervention with surgery is less well understood. However, the implication of end-stage degenerative intervertebral disc disease with vertical collapse of the vacuum disc is that in this scenario clinical outcomes with decompression alone would be expected to be inferior compared with fusion. ${ }^{7}$ A vacuum disc may contribute to radicular and low back pain because of accentuated foraminal and lateral recess stenosis, ${ }^{8,9}$ and painful preferential neo-innervation of the end plates. ${ }^{10}$ Thus, the concern is that performing transforaminal endoscopic decompression without a vertical height restoration interbody fusion procedure would potentially be a disservice to a patient in whom reliable preoperative prognosticators would suggest improved outcomes if a decompression were combined with fusion. Currently, such clinical surgical outcome prognosticators are lacking in the literature. ${ }^{11,12}$

Nowadays, there is a growing demand for valuebased health care measures to serve the aging baby boomer population. ${ }^{13,14}$ A primary simplifiedpossibly stand-alone-interbody fusion surgery ${ }^{15}$ could, in fact, prove more cost effective and provide improved clinical outcomes if select patients could be reliably identified preoperatively. The extensive combined published ${ }^{11,12,16-21}$ (level 3) and unpublished (level 5) clinical experience-and specifically the experience of the senior author of the present study, A.Y., with his case series of more than 10000 individual patients whom he treated during the last 28 years for common nonspecific low back pain ${ }^{16}$ led to the empiric creation of patient selection criteria and successful clinical protocols to treat low back and radicular pain, suggesting that such prognosticators of successful clinical outcome with the lumbar transforaminal endoscopic decompression procedure do exist but need to be further defined.

The advantages of endoscopic transforaminal decompression surgery are obvious: fewer postopera- tive complications, a shorter interval for return to work and social reintegration, less time to postoperative narcotic independence, and an overall reduced use of painkillers. ${ }^{22}$ The latter problem is of significance in the context of the narcotic abuse epidemic in the United States. ${ }^{23,24}$ Less approach-related access trauma and reduced surgical pain in combination with an overall push by patients and insurance providers to perform simplified lumbar decompression and fusion surgeries in a more cost-effective outpatient setting have led to a substantial increase in lumbar endoscopic surgeries. ${ }^{25,26}$ Compared with traditional open approaches, the endoscopic transforaminal surgery has been shown to be associated with a lower burden to the patient because of its simplicity. ${ }^{27}$ Patient acceptance is higher because of fewer anesthesiarelated problems (postoperative nausea), ${ }^{28}$ and equivalent favorable clinical outcomes. ${ }^{29-38}$ In short, it is an elegant method to treat the patients who experience lumbar radiculopathy in an ambulatory surgery center-often under local anesthesia with sedation, and at a reduced cost. ${ }^{39}$ Greater cost reduction is also accomplished by identifying and treating the pain generator earlier ${ }^{39}$ in the disease process and eliminating the expense of long-term failed nonsurgical treatment that currently results in more surgically morbid and expensive fusion techniques. ${ }^{35-42}$

Significant advances in videoendoscopic technology ${ }^{11,12}$ in combination with more reliable motorized decompression tools have contributed to the rise of more complex decompression procedures. ${ }^{30}$ The efficacy and safety of endoscopic transforaminal decompression have been evaluated for both herniated $\operatorname{disc}^{31}$ and spinal stenosis. ${ }^{27,32}$ The most significant upside to endoscopic procedures of the spine lies in its improved direct visualization of the foraminal and discal anatomy both in the epidural space and inside the disc. ${ }^{27}$ Thus, routine videoendoscopic exploration at high magnification in areas that were ordinarily difficult to directly visualize with traditional microsurgical techniques using the operating microscope or loupes, has afforded the ability to better study the degenerative processes within the spinal canal, including the area medial to the facet joints, the lateral recess, under the dural sack, the neuroforaminae, and, most importantly, within the intervertebral disc itself.

The "inside-out" YESS intradiscal decompression technique was pioneered by the senior author of this publication, Anthony Yeung, who popularized its utility not just for transforaminal discecto- 
$m y^{29-32}$ but also for direct visualization of intradiscal pathology during the discectomy procedure. ${ }^{35,36}$ Yeung's "inside-out" technique emphasizes the intervertebral disc as the common source of pain generation. Therefore, intradiscal visualization and intradiscal therapy are the mainstays of Yeung's approach. The "inside-out" technique allows for visualized pathoanatomy to be graded. This intradiscal degenerative destructive process of the nucleus may be recorded as cavitation, fissuring, and delamination from the end plates. ${ }^{41}$ To date, the correlation of these endoscopically visualized intradiscal findings with plain x-ray imaging has not been made.

The need for better prognosticators of successful clinical outcome following spinal decompression surgeries is corroborated by the recent debate on the prognostic value of magnetic resonance imaging (MRI) in therapeutic decision-making. ${ }^{43-45}$ In particular, $22 \%$ to $51 \%$ of asymptomatic individuals have been shown to demonstrate MRI irregularities in their lumbar spines, with this number increasing between $57 \%$ and $80 \%$ for those older than 60 years. ${ }^{46,47}$ Even in symptomatic patients, the presence of different types of abnormalities on MRI demonstrates little correlation with self-reported pain and appears to have a negligible effect on patient care or outcome. ${ }^{48}$ This low specificity of advanced crosssectional imaging requires that their results be closely correlated with history and physical examination at the time the care is delivered. The diagnostic accuracy of preoperative lumbar MRI has been tested either with direct visualization during surgery or with clinical outcome studies. ${ }^{12}$ Some studies have used surgery as the gold standard to assess the accuracy of lumbar MRI scan, with some analyses correlating the imaged neural impingement with directly intraoperatively visualized pathology. ${ }^{49,50}$ However, the prognostic clinical value of MRI grading of disc degeneration according to Pfirmann ${ }^{51}$ - whose classification is based purely on a description of signal inhomogeneity of the lumbar intervertebral disc on cross-sectional MRI scans-is poorly understood with respect to surgical outcomes.

Therefore, development of other alternate prognosticators is necessary, and the focus of this study was simple: Record the frequency of "vacuum" degenerative intervertebral discs being found during routine lumbar transforaminal endoscopic decompression surgery and correlate it with preoperative $\mathrm{x}$-ray grading of the surgical level to allow correlative analysis to clinical outcomes. The intent was to use this information to aid in the advancement of an improved clinical algorithm with higher diagnostic accuracy for preoperative surgical planning in patients with symptomatic sciatica-type low back and leg pain due to a herniated disc or spinal stenosis. In short, the goal was to provide the basis for the development of more appropriate surgical selection criteria for patients who would be better off with a primary vertical height restoration procedure, such as a stand-alone lordotic endoscopic wedge lumbar interbody fusion (LEW-LIF), ${ }^{52}$ rather than a decompression alone.

\section{MATERIALS AND METHODS}

In 2006, the Center for Advanced Spine Care of Southern Arizona established an outpatient spinal surgery program for the treatment of lumbar herniated disc and spinal stenosis. Several years ago, the authors of this publication noticed serendipitously and independently that many of their patients with severely advanced degeneration treated for sciatica-type low back and leg pain due to spinal stenosis or herniated disc during needle insertion had vacuum disc with negative intradiscal pressures manifested by a spontaneous air discogram and void of any organized tissue. This caused the primary author to perform routine intradiscal visualization and probing after air discogram during epiduroscopic "outside-in" endoscopic transforaminal discectomy. This probing was done before placement of the working cannula inside the disc for direct visualization of the intradiscal pathoanatomy. The results presented here are based on a prospective data collection on consecutive patients who were operated on by the treating surgeon (K.U.L.) between 2013 and 2016. The other two authors of this paper contributed their level 5 opinion based on their focus on the disc as a primary source of nonspecific low back and radicular leg pain with data interpretation, classification of direct visualization of intraoperative disc degeneration, definition of clinical categories, and discussion of their possible use as clinical prognosticators of successful outcome after endoscopic transforaminal decompression.

\section{Patient Population}

All patients in this case series provided informed consent. This consecutive case series included 200 
Table 1. Frequency of surgical levels $(N=200)$.

\begin{tabular}{lrccc}
\hline & Frequency & Percent & Valid Percent & Cumulative Percent \\
\hline Valid & 1 & 0.5 & 0.5 & 0.5 \\
L1/L2 & 1 & 0.5 & 0.5 & 1 \\
L2-L4 & 1 & 0.5 & 0.5 & 1.5 \\
L2-L5 & 2 & 1 & 1 & 2.5 \\
L2/L3 & 3 & 1.5 & 1.5 & 4 \\
L3-L5 & 6 & 3 & 3 & 7 \\
L3-S1 & 1 & 0.5 & 0.5 & 7.5 \\
L3/L4 & 16 & 8 & 8 & 15.5 \\
L3/L4, L5/S1 & 1 & 0.5 & 0.5 & 16 \\
L4-S1 & 26 & 13 & 13 & 29 \\
L4/L5 & 103 & 51.5 & 51.5 & 80.5 \\
L5/S1 & 39 & 19.5 & 19.5 & 100 \\
Total & 200 & 100 & 100 & \\
\end{tabular}

patients seen in our clinic who underwent percutaneous endoscopic foraminotomy and microdiscectomy at 236 levels. The frequency of surgical level distribution is listed in Table 1. Slightly more than half the patients underwent a single-level transforaminal decompression at L4/L5 (51.5\%), followed by an additional $19.9 \%$ of patients who had a single-level surgery at L5/S1. The third most common surgical scenario was a 2-level L4 to S1 decompression (13.0\%). The mean follow-up was 41.85 months, ranging from 24 to 68 months (SD, 13.02 months) at the time this study was concluded. Average age of participants was 61.44 years, ranging from 25 to 93 years (SD, 13.1 years), showing a near-normal distribution. Most patients were between ages 50 and 75 (Figure 1). Of the 200 patients, 104 were female $(52 \%)$ and 96 were male (48\%). Of the 200 patients, 87 (43.5\%) had surgery on the left side, compared with $67(33.5 \%)$ who underwent transforaminal decompression on the right side. An additional 46 patients (23\%) underwent bilateral decompression.

The inclusion criteria were: (1) clinical signs of lumbar radiculopathy, dysesthesia, or decreased motor function; (2) imaging evidence of foraminal or lateral recess stenosis (criteria described below) demonstrated on preoperative MRI scans; (3) unsuccessful nonoperative treatment including physical therapy and transforaminal epidural steroid injections (TESI) for at least 12 weeks. Patients exhibiting the following were excluded from this study: segmental instability on preoperative extension/flexion radiographs, or severe central stenosis (less than $100 \mathrm{~mm}^{2}$ ). ${ }^{38}$ Inclusion/ exclusion criteria were used with the intent of minimizing the effect of other confounding factors.

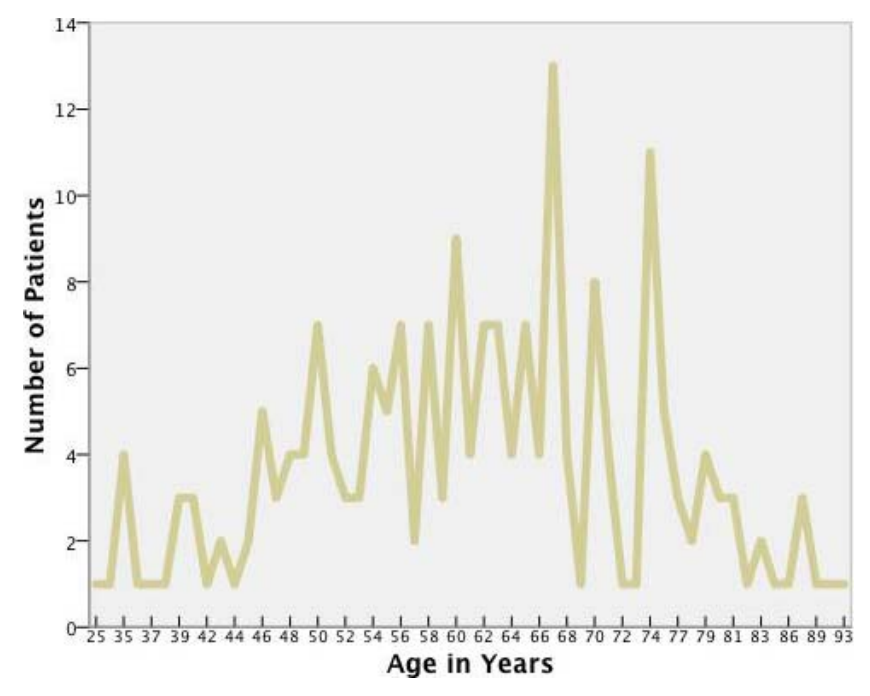

Figure 1. Age distribution of surgical patients who underwent endoscopic transforaminal foraminoplasty and discectomy.

\section{Preoperative Workup and Surgical Decision-Making}

Patients were worked up with a thorough history, physical examination, and imaging studies as described below. Patients were subjected to an interventional diagnostic workup with lidocaine containing TESI using biplanar fluoroscopic image intensifier guidance. ${ }^{53,54}$ A mixture of $1 \mathrm{~mL}$ of Depo Medrol Sterile Aqueous Suspension (methylprednisolone acetate; McKesson, Irving, Texas) and 20 $\mathrm{mg} / 1 \mathrm{~mL}$ of lidocaine $1 \%$ was injected into the "safe triangle," defined by pedicle, the exiting nerve root, and the lateral border of the intervertebral disc and vertebral body. ${ }^{55}$ A radiopaque contrast agent, Isovue-300, was used as an adjunct to demonstrate the outline of the target nerve root and the absence of any epidural, intravascular, or intradural flow of contrast. All injections were performed in a suite equipped with a radiolucent pain management table and biplanar fluoroscopy at the spinal level believed to be the best match between clinical presentation and MRI findings. Patients were asked to grade their pain prior to and immediately after the injection as well as at a 2-week follow-up visit, using the visual analog score (VAS) ${ }^{56}$ Patients were also asked to rate their pain using the Glasgow Pain Questionnaire. ${ }^{57}$ A TESI was considered diagnostic if the patient reported an immediate (within 15 minutes) VAS reduction of greater than $50 \%{ }^{57}$ Patients were also asked to verbalize whether their pain was unchanged, their pain improved, or if they were pain-free without residual symptoms. Patients with conclusive diagnostic workup with matching clinical symptoms, MRI findings, diagnostic TESI 


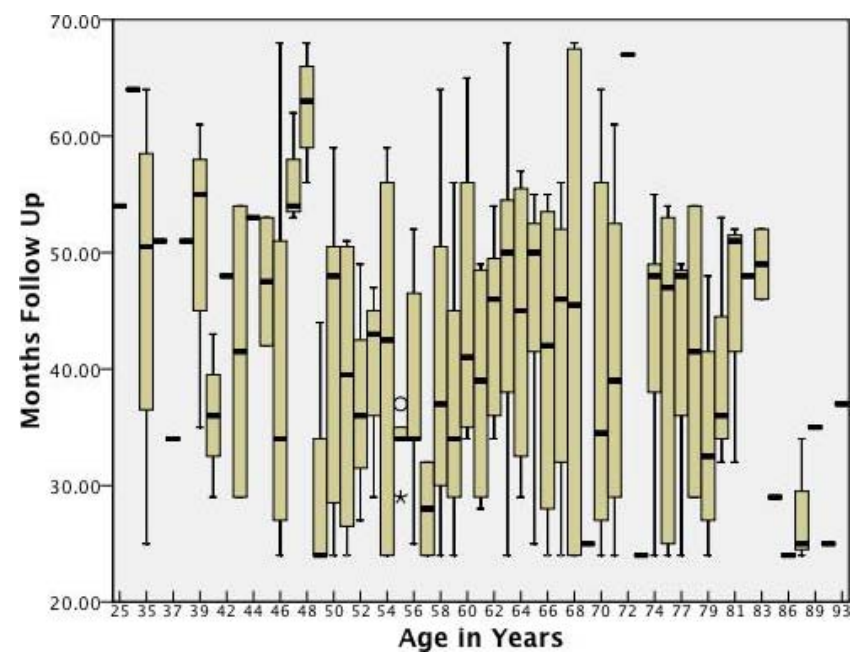

Figure 2. Plot of length of follow-up against age showing follow-up in most of the older patients with intraoperatively visualized vacuum disc to be much longer than 24 months.

response, and supporting history and physical examination were ultimately deemed appropriate surgical candidates for the endoscopic transforaminal decompression procedure.

\section{Clinical Follow-up and Primary Outcome Measures}

Radiographs and MRI images were obtained preoperatively and graded as described below for all surgical patients. Typically, patients returned for clinical follow-up at 6 weeks postoperatively, and at $3,6,12$, and 24 months, respectively. After the 2year follow-up appointment, patients were seen on an annual or biannual basis. Results reported herein were computed from data obtained at 2-year followup. Plotting the length of follow-up data against age showed follow-up in most of the older patients with intraoperatively visualized vacuum disc to be much longer than than 24 months, and in most patients longer than 30 months (Figure 2).

Primary clinical outcome measures were reductions in the VAS for leg pain ranging from no pain (0) to worst pain (10) done by both the patient and the treating surgeon (K.U.L.) using the Macnab criteria. $^{58}$ Briefly, follow-up outcome results were classified as excellent (little pain, able to perform desired activities with few limitations); good (occasional pain or dysesthesia, able to perform daily activities with minor limitations and did not need pain medication); fair (level of pain somewhat improved but continued to need pain medication; or poor (function worsened or needed additional surgery to address symptoms). At each follow-up visit, the clinical outcome of each patient was graded using these modified Macnab and criteria. ${ }^{59}$ The patient was also asked to select a VAS ${ }^{56}$ and to rate functioning using the Glasgow Pain Questionnaire. ${ }^{58}$ Ultimately, these standardized outcome measures were used to determine the prognostic value of an intraoperatively visualized vacuum disc and its impact on clinical outcome.

\section{Radiologic Evaluation of Vacuum Disc and Stenosis Classification}

Preoperative plain film studies of the surgical level were evaluated for the presence of a radiographic sign of "vacuum phenomenon." A morphologic description of the vacuum phenomenon on the basis of computed tomography imaging analysis has recently been published by suggesting 3 radiographic categories $^{60}$ : (1) spot (less than $2 \mathrm{~mm}$ in diameter), (2) linear (fissuring less than $2 \mathrm{~mm}$ thick), and (3) island (cavity defect). The presence of any of these features on plain films was considered a vacuum phenomenon. Preoperative MRI scans were analyzed for foraminal and lateral recess stenosis. Lee's classification was used to define the location of the offending pathology within the neuroforamen by dividing it from medial to lateral into entry (dura to pedicle; zone 1), middle (medial pedicle wall to center pedicle; zone 2), and exit (center pedicle to the lateral border of the facet joint; zone 3 ) zones. ${ }^{61}$ Foraminal and lateral recess stenoses were stratified according to the main offending pathology: extruded herniated disc, disc bulge, and disc bulge with concomitant bony stenosis. Disc herniations were further classified as upward, downward, migrated, or centered around this disc space using Lee's 4-zone classification. ${ }^{62}$ In the entry zone, Lee described hypertrophy of the superior articular facet as the predominant pathology. ${ }^{62}$ In the mid zone, it was often due to an osteophytic process underneath the pars interarticularis, and in the exit zone due to a subluxed and hypertrophic facet joint. ${ }^{62}$ These classification systems have been previously applied by the author. ${ }^{11,12,27,33,34}$ The heights of the posterior intervertebral disc and lumbar foramina were evaluated according to Hasegawa et al., ${ }^{63}$ who described a lumbar neuroforaminal height of $15 \mathrm{~mm}$ or more as normal and reduced posterior intervertebral disc height of 3 to $4 \mathrm{~mm}$ as suggestive of spinal stenosis.

Preoperative sagittal and axial MRI images were graded and used to assess the location and extent of foraminal stenosis. Only patients with stenotic lesions (whether due to bony stenosis, extruded disc 
herniation, or contained disc bulge) producing a neuroforaminal width of $3 \mathrm{~mm}$ or less on the sagittal MRI cuts or lateral recess height of $3 \mathrm{~mm}$ or less on the axial MRI cuts were considered "stenotic" and treated surgically. The degree of lumbar intervertebral disc degeneration was also graded using the MRI classification system published by Pfirrmann et al., ${ }^{51}$ in which grade I characterizes the MRI appearance of the surgical disc as "homogeneous with bright hyperintense white signal intensity and normal disc height...," and grade $\mathrm{V}$ as an inhomogeneous disc "with hypointense black signal intensity. There is no difference between the nucleus and the annulus. The disc space is collapsed...."51

The MRI grading of the exiting nerve root compression at the surgical level was recorded using the categories of the Lee classification published in $2010 .{ }^{64}$ Grade 0 refers to normal neuroforamen; grade 1, mild foraminal stenosis showing perineural fat obliteration in 2 opposing directions; grade 2, moderate foraminal stenosis showing perineural fat obliteration in 4 directions; and grade 3, severe foraminal stenosis showing morphologic changes in the nerve root. ${ }^{64}$ For the purpose of this analysis, patients with MRI grades 2 and 3 were classified as having exiting nerve root compression due to foraminal stenosis at the surgical level.

\section{Surgical Techniques}

All surgical procedures employed the endoscopic transforaminal approach using the "outside-in" technique. During initial needle insertion a vacuum disc was often noted due to negative intradiscal pressures and manifested by a spontaneous air discogram. This caused the primary author to perform routine intradiscal visualization and probing after air discogram during epiduroscopic "outside-in" endoscopic transforaminal discectomy. This probing was done before placement of the working cannula inside the disc for direct visualization of the intradiscal pathoanatomy using the inside-out technique to check for the presence of organized intervertebral disc tissue and to visualize the morphology of disc degeneration.

The first author's modification of the "outside-in" technique involves placing the working sheath into the lower portion of the neuroforamen, thus retracting and avoiding the exiting nerve root. No part of the cannula tip or the endoscope (4.1-mm inner working channel; asap endoscopic products $\mathrm{GmbH}$, Umkirch, Germany) is positioned in the disc space during this portion of the procedure. The surgical technique used by the author (originally popularized by Hoogland et al. ${ }^{65}$ and Schubert and Hoogland ${ }^{66}$ ) employs a primary foraminoplasty in patients with or without lateral stenosis for the treatment of herniated disc. Procedures were performed in a prone position under local anesthesia, and deep sedation in all patients. Techniques to define the skin entry point and the surgical trajectory have been described in previous literature. $^{67,68}$

For the foraminoplasty, bone from the hypertrophied superior and inferior articular process was removed with endoscopic chisels, drills, Kerrison rongeurs, and percutaneous trephines. The endoscopic drills and rongeurs were deployed inside the center working cannula of the endoscope to lessen the risk of dysesthesia and irritation of the exiting nerve root and its dorsal root ganglion. Additional cannulated reamers and drills (maxmorespine by Hoogland Spine Products, Unterföhring, Germany) measuring 7 and 9 $\mathrm{mm}$ in diameter intended to be used over a guide wire without the protective working cannula were available but used only in 3 cases to remove the lateral overhang from large hypertrophied facet joints to further minimize the risk of dysesthesia of the exiting nerve root and irritation of its dorsal root ganglion. In other words, the entire decompression was typically performed under continuous direct videoendoscopic visualization, and no part of the decompression procedure is done percutaneously with only indirect fluoroscopic imaging.

The foraminoplasty was facilitated by changing the trajectory of the instruments to aim for the compressive pathology identified on preoperative studies; that is, the bony decompression was focused on removing the relevant stenotic process identified on preoperative imaging studies using categories of the Lee classification (exit, mid, and entry zone). For example, a stenotic process in the entry zone would typically require a more substantial subtotal resection of the superior articular process, starting at the tip of the superior articular process to be able to access the lateral recess.

The intradiscal probing was done after the initial foraminoplasty was completed and the intervertebral disc was exposed. A pituitary rongeur was advanced into the intervertebral disc space through annular tears associated with extruded disc herniations, or through a small annular window in case of contained disc herniation. In every patient, this 

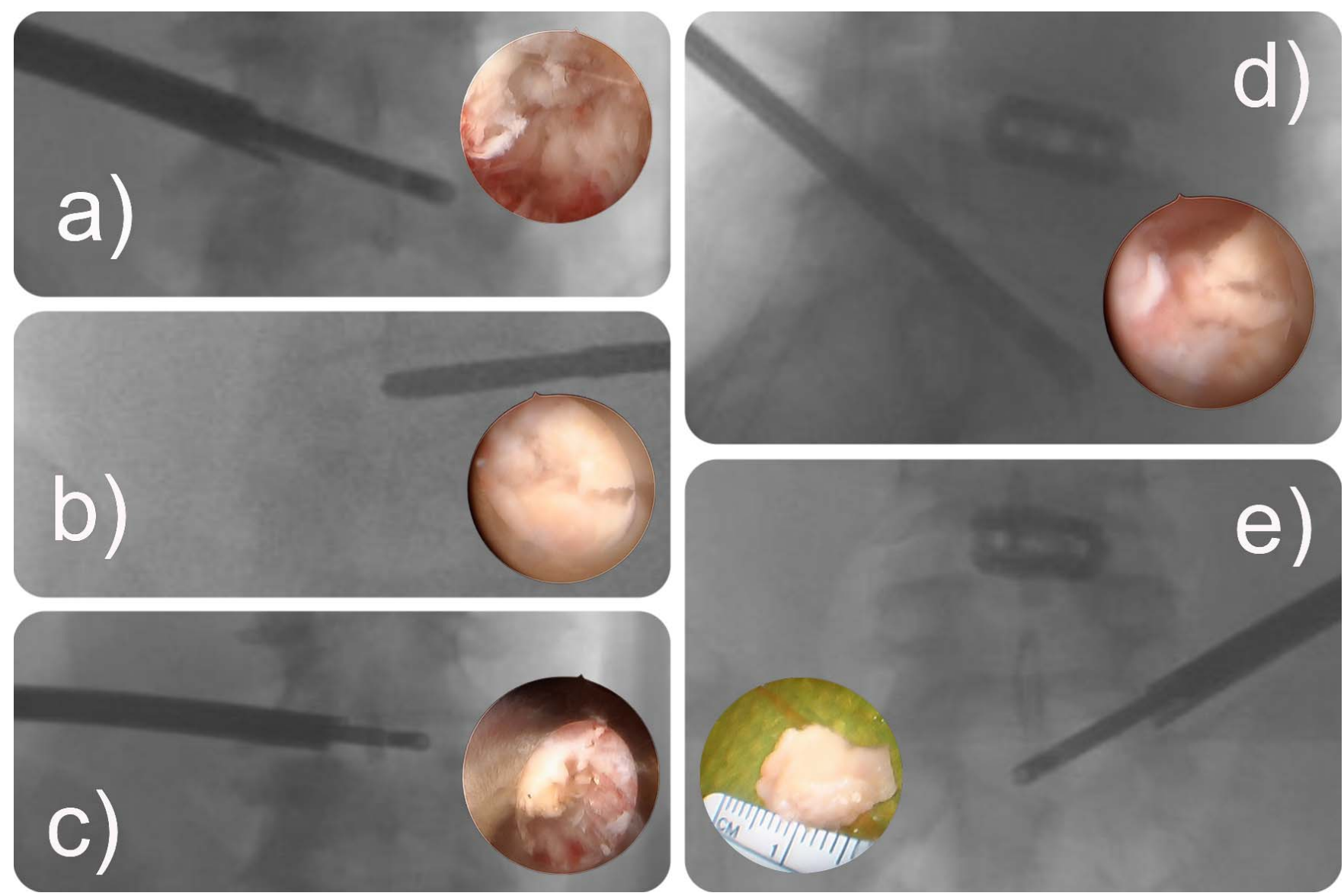

Figure 3. Intraoperative fluoroscopic and associated endoscopic images taken during transforaminal microdiscectomy and foraminoplasty with initial intradiscal probing of the surgical intervertebral disc after foraminoplasty using the "inside-out" technique to test for the presence of a vacuum disc. Vacuum disc with the pituitary rongeur advanced to the opposite annulus at the L4/L5 and L5/S1 level: (a) endoscopic view showing cavitation, (b) endoscopic view showing fissuring, (c) endoscopic view showing cavitation and delamination, (d) endoscopic view showing fissuring and delamination, and (e) large piece of degenerated disc delaminated of the $\mathrm{S} 1$ end plate.

testing of the integrity of the nucleus pulposus was performed before initiation of the discectomy, during which the working cannula of the spinal endoscope was inserted into the disc space in keeping with the standard YESS "inside-out" technique.

\section{Visualized Pathology}

The visualized compressive pathology was recorded for each patient and described either as (1) extruded disc herniation, (2) contained disc herniation, or (3) bony spinal stenosis. Furthermore, the compressive pathology directly visualized during the endoscopic transforaminal decompression surgery was recorded by location within the neuroforamen using corresponding categories as in the radiographic zone classification systems by Lee et al. ${ }^{61}$ employed herein, either in its entry, mid, or exit zone, or a combination thereof. The location of the stenotic lesion in the triangular safe zone between exiting and traversing nerve root and the inferior pedicle described by Kambin et al. ${ }^{67,68}$ (regardless of whether due to herniated disc, stenosis as a result of bony osteophytes, or facet hypertrophy) was recorded and compared to the radiologically classified and recorded location of the stenotic lesion underneath the facet joint complex. The inability to pass the 2-mm diameter probe into the lateral recess was considered confirmatory intraoperative evidence of lateral recess stenosis as described by Hasegawa et al. ${ }^{63}$ to be associated with symptomatic spinal stenosis $80 \%$ of the time.

As described above, after completion of the initial foraminoplasty and before discectomy each intervertebral disc space was probed by attempting to advance a pituitary rongeur through the entire disc to the opposite annulus on an intraoperatively obtained anteroposterior fluoroscopic image. A disc was recorded as "vacuum" if a $3.8-\mathrm{mm}$ diameter pituitary could be advanced across the disc space without resistance to the opposite annulus (Figure 3 ). The probing was only done on the surgical side, 
and patients with bilateral decompression had the procedure done only from the side that was approached first. In such cases, the endoscope was introduced into the intervertebral disc before commencing the discectomy employing the "insideout" YESS technique to visualize the degenerative destructive process directly, which was grossly divided into 3 categories in accordance with Murata et al. ${ }^{60}$ : (1) fissuring - large horizontal clefts within some residual disorganized disc tissue - and (2) cavitation-an empty disc space. In addition, delamination of any residual disc tissue from the end plates and any combination of these 3 categories were recorded. Patients in whom the pituitary rongeur could not be advanced into the disc were classified as "stable nucleus."

\section{Correlative Analysis of Preoperative Radiographs, Visualized Pathology, and Surgical Outcomes}

For the clinical outcome analysis, cross-tabulation statistics and measures of association were computed for 2-way tables using IBM SPSS Statistics software, version 25.0 (Armonk, NY). Descriptive statistic measures were used to calculate the mean, range, and SD as well as percentages. Cross-tabulation methods were used to assess for any statistically significant association between clinical outcome data based on the modified Macnab criteria, VAS, Glasgow Pain Score, stenosis zone classification, MRI classification of disc degeneration, MRI grading of foraminal and lateral recess stenosis, definition of the location of any herniated disc, foraminal height, width, plain radiograph classification of vacuum phenomenon, and surgeon visualization of intradiscal degeneration of a "vacuum disc." Pearson $\chi^{2}$ and Fisher exact test were employed as statistical measures of association. Expected cell counts, continuity corrections, and likelihood ratios were calculated for some analyses. The VAS reductions were compared and tested for statistically significant differences between preoperative and postoperative values using the paired $t$ test.

The plain radiograph sensitivity of accurately predicting a vacuum intervertebral disc (X-Ray Positive; true-positive rate; TP) confirmed by intraoperative visualization was calculated as the percentage of patients (X-Ray Positive) among the radiculopathy patients who were correctly identified by $\mathrm{x}$-ray to have a vacuum disc. False-negatives (FNs) were patients with intraoperatively visualized vacuum disc whose preoperative lumbar $\mathrm{x}$-rays were negative (X-Ray Negative) for vacuum phenomenon.

The diagnostic $\mathrm{x}$-ray sensitivity for accurately predicting a vacuum disc during the endoscopic transforaminal decompression procedure was calculated as follows:

$$
\begin{gathered}
\text { X-Ray Positives with } \\
\frac{\text { intraoperatively visualized vacuum disc }(\mathrm{TP})}{\mathrm{TP}+\mathrm{X}-\mathrm{R} \text { ay Negatives with }} \\
\text { intraoperatively visualized vacuum disc }(\mathrm{FN})
\end{gathered}
$$

The plain radiograph specificity (true-negative rate) of accurately predicting the absence of a vacuum intervertebral disc during spinal endoscopy was calculated as the percentage of patients correctly identified as not having a vacuum intervertebral disc. False-positives were defined as X-ray Positives without endoscopically visualized vacuum disc.

The diagnostic x-ray specificity for accurately predicting a vacuum disc during the endoscopic transforaminal decompression procedure was calculated as follows:

\section{X-Ray Negatives without}

intraoperatively visualized vacuum disc (TN)

TN + X-Ray Positives without visualized

intraoperatively visualized vacuum disc (FP)

The positive predictive value (PPV) of a preoperative lumbar radiograph to accurately predict a vacuum disc during a routine "inside-out" transforaminal endoscopic decompression procedure was calculated as follows:

$$
\begin{gathered}
\text { X-Ray Positives with } \\
\frac{\text { endoscopically visualized vacuum disc }}{\mathrm{TP}+\text { FP X-Ray Positives }} \\
\text { without visualized vacuum disc } \\
=\frac{\mathrm{TP}}{\mathrm{TP}+\mathrm{FP}}
\end{gathered}
$$

Disease prevalence due to symptomatic neural compression and the vacuum disc was calculated as the percentage of the patient study group with intraoperatively confirmed, endoscopically direct visualized spinal stenosis, or herniated disc.

$$
\text { Disease prevalence }=\frac{\mathrm{TP}+\mathrm{FP}}{\mathrm{TP}+\mathrm{FN}+\mathrm{FP}+\mathrm{TN}}
$$

As a measure of statistical bias, the accuracy (ACC) of a diagnostic preoperative lumbar X-ray 
scan for predicting the presence of a vacuum disc and for successful clinical outcome following a transforaminal endoscopic decompression procedure was calculated as follows:

$$
\mathrm{ACC}=\frac{\mathrm{TP}+\mathrm{TN}}{\mathrm{TP}+\mathrm{FN}+\mathrm{FP}+\mathrm{TN}}
$$

The confidence intervals for the likelihood ratios were calculated using the "log method" according to Altman et al. ${ }^{69}$ The confidence intervals for the positive predictive values are the standard logit confidence intervals as described by Mercaldo et al. $^{70}$

\section{RESULTS}

The age distribution of our patient population was nearly normal (Figure 1). Of the 200 patients who underwent outpatient endoscopic transforaminal decompression (Table 2), excellent results according to the Macnab criteria were obtained in all of the patients with extruded disc fragment ( 8 of 200). In this group, the mean VAS decreased from $6.1 \pm 2.6$ preoperatively to $1.9 \pm 1.4$ at the final follow-up $(P<.01)$. Patients with contained disc herniations (62 of 200) had excellent and good results $82.2 \%$ of the time. In this group, the mean VAS decreased from $6.9 \pm 1.7$ preoperatively to $2.2 \pm 1.1$ at final follow-up $(P<.01)$. In the spinal stenosis group (130 of 200), 81.5\% of patients had excellent to good results and the mean VAS decreased from $6.3 \pm 1.5$ preoperatively to $2.1 \pm 1.2$ at final follow-up $(P<.01)$.

There were no major approach-, surgical-, or anesthesia-related complications. Reherniations were not observed. Failure of pain relief without significant improvement of walking endurance occurred in 1 patient with stenosis and in 1 patient with contained disc herniation, both of which had associated spinal deformity with scoliosis. Of the 130 patients with foraminal stenosis, the neuroforaminal entry zone was involved in 41 patients $(31.5 \%)$, the mid zone in 68 patients $(52.3 \%)$, and exit zone in 21 patients $(16.2 \%)$. The subset of patients with contained disc herniation had more advanced degenerative changes on the basis of the Pfirrmann et al. ${ }^{51}$ MRI grading system. Nearly all patients with contained disc herniations and fair (10 of $62 ; 16.1 \%$ ), and poor ( 1 of $62 ; 1.6 \%$ ) outcomes received grade $\mathrm{V}$ and some grade IV on the Pfirrmann scale ${ }^{51}$ to characterize the advanced degeneration of the surgical lumbar disc.
Table 2. Surgical outcomes versus diagnosis $(N=200)$.

\begin{tabular}{|c|c|c|c|c|}
\hline \multirow[b]{2}{*}{ Outcome } & \multicolumn{3}{|c|}{ Diagnosis } & \multirow[b]{2}{*}{ Total } \\
\hline & Contained Disc & Extruded Disc & Stenosis & \\
\hline \multicolumn{5}{|l|}{ Excellent } \\
\hline Count & 17 & 8 & 23 & 48 \\
\hline Within diagnosis, $\%$ & 27.4 & 100 & 17.7 & 24 \\
\hline \multicolumn{5}{|l|}{ Fair } \\
\hline Count & 10 & 0 & 23 & 33 \\
\hline Within diagnosis, $\%$ & 16.1 & 0.0 & 17.7 & 16.5 \\
\hline \multicolumn{5}{|l|}{ Good } \\
\hline Count & 34 & 0 & 83 & 117 \\
\hline Within diagnosis, \% & 54.8 & 0.0 & 63.8 & 58.5 \\
\hline \multicolumn{5}{|l|}{ Poor } \\
\hline Count & 1 & 0 & 1 & 2 \\
\hline Within diagnosis, $\%$ & 1.6 & 0 & 0.8 & 1 \\
\hline \multicolumn{5}{|l|}{ Total } \\
\hline Count & 62 & 8 & 130 & 200 \\
\hline Within diagnosis, $\%$ & 100 & 100 & 100 & 100 \\
\hline
\end{tabular}

Analyzing the cross-tabulation frequency of diagnostic X-ray Positive grading in patients with visualized vacuum disc (Table 3) showed truepositive (35 patients) and false-negative (89 patients), compared with an X-ray Negative grading in patients without intraoperatively visualized vacuum disc-false-positive (2 patients) and true-negative (74 patients) - allowed for calculation of sensitivity (28.2\%), specificity (97.4\%), and PPV (94.6\%) of preoperative diagnostic $x$-ray in relation to intraoperatively visualized presence of the vacuum disc during subsequent endoscopic decompression surgery. The disease prevalence (presence of a vacuum disc) in the patient population of this study was calculated as $62 \%$. The accuracy as a measure of statistical bias was calculated to be 0.55 .

The distribution of a vacuum disc was nearly even between both sexes, with no statistically significant difference being found (Tables 4 and 5). Plotting the number of patients with and without a vacuum phenomenon noted on preoperative $\mathrm{x}$-rays and the

Table 3. Cross-tabulation frequencies of $x$-ray grading in patients with and without visualized vacuum disc to calculate sensitivity and specificity $(N=200)$.

\begin{tabular}{|c|c|c|c|}
\hline \multirow[b]{2}{*}{ Vacuum on X-Ray } & \multicolumn{3}{|c|}{ Intraoperative Hollow Disc } \\
\hline & No & Yes & Total \\
\hline \multicolumn{4}{|l|}{ No } \\
\hline Count & 74 & 89 & 163 \\
\hline Within intraoperative hollow disc, \% & $97.4^{\mathrm{a}}$ & 71.8 & 81.5 \\
\hline \multicolumn{4}{|l|}{ Yes } \\
\hline Count & 2 & 35 & 37 \\
\hline Within intraoperative hollow disc, $\%$ & 2.69 & $28.2^{\mathrm{b}}$ & 18.5 \\
\hline \multicolumn{4}{|l|}{ Total } \\
\hline Count & 76 & 124 & 200 \\
\hline Within intraoperative hollow disc, $\%$ & 100 & 100 & 100 \\
\hline
\end{tabular}

${ }^{\text {a }}$ Preoperative lumbar firm specificity to accurately diagnose an absent vacuum disc (true-negative rate).

${ }^{b}$ Preoperative lumbar firm sensitivity to accurately diagnose a vacuum disc (truepositive rate). 
Table 4. Intraoperative Hollow Disc $\times$ Sex cross-tabulation: frequency of intraoperatively visualized vacuum disc by $\operatorname{sex}(N=200)$.

\begin{tabular}{lrrr}
\hline & \multicolumn{3}{c}{ Sex } \\
\cline { 2 - 3 } Intraoperative Hollow Disc & F & M & Total \\
\hline No & 39 & 37 & 76 \\
Yes & 65 & 59 & 124 \\
Total & 104 & 96 & 200 \\
\hline
\end{tabular}

number of patients with and without intraoperatively visualized vacuum disc versus age showed normal histogram distribution for patients without a vacuum phenomenon on preoperative $\mathrm{x}$-rays (Figure 4, top left). In contrast, patients with a vacuum phenomenon on their preoperative lumbar plain film studies showed a much higher distribution between the ages of 65 and 77 years (Figure 4, top right). The age distribution for patients without intraoperatively visualized vacuum disc was not normal (Figure 4, bottom left). In comparison, intraoperatively vacuum discs were predominantly visualized with the intradiscal "inside-out" placement of the spinal endoscope in patients with ages ranging from 42 to 82 years (Figure 4, bottom right).

Analyzing clinical outcomes in relation to the presence of an intraoperatively visualized vacuum disc revealed fair and poor outcomes according to Macnab criteria in patients with concomitant vacuum and collapsed $(<3 \mathrm{~mm}$ in posterior disc height). In fact, all of the 33 patients with fair outcome fit that category: vacuum and collapsed disc (Tables 6 and 7). In contrast, 40 of the 48 patients with excellent clinical outcome $(83.3 \%)$ had a preserved nucleus and posterior disc height $(>3$ $\mathrm{mm})$. A total of 69 of the 117 patients with good clinical outcomes $(58.97 \%)$ from the endoscopic

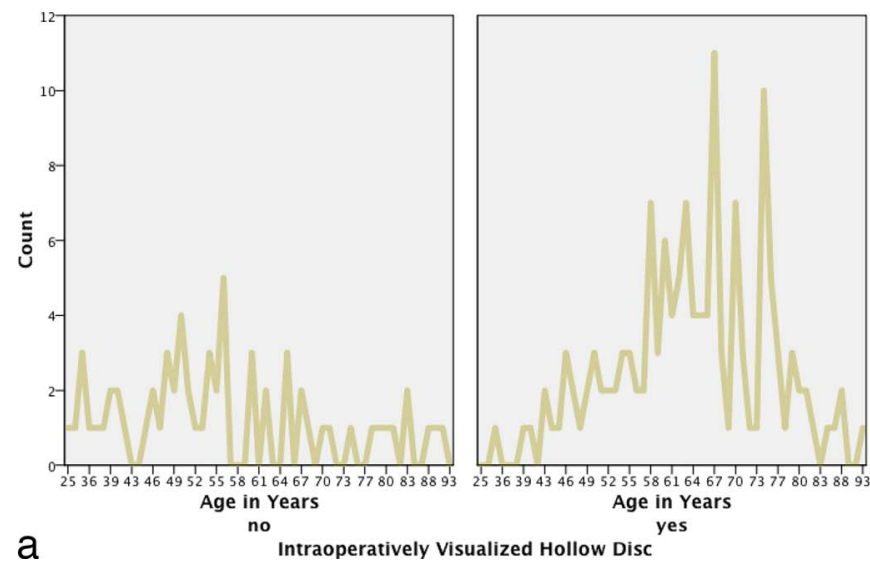

Table 5. Statistical analyses for frequency of intraoperatively visualized vacuum disc by sex $(\mathrm{N}=200$ valid cases $)$.

\begin{tabular}{|c|c|c|c|c|c|}
\hline & Value & df & $\begin{array}{c}\text { Asymptotic } \\
\text { Significance } \\
\text { (2-Sided) }\end{array}$ & $\begin{array}{c}\text { Exact } \\
\text { Sig. } \\
\text { (2-Sided) }\end{array}$ & $\begin{array}{c}\text { Exact } \\
\text { Sig. } \\
\text { (1-Sided) }\end{array}$ \\
\hline Pearson $\chi^{2}$ & $.023^{\mathrm{a}}$ & 1 & .879 & & \\
\hline Continuity correction ${ }^{\mathrm{b}}$ & .000 & 1 & .995 & & \\
\hline Likelihood ratio & .023 & 1 & .879 & & \\
\hline Fisher exact test & & & & .885 & .497 \\
\hline
\end{tabular}

transforaminal decompression had a vacuum intervertebral disc found on "inside-out" inspection of the integrity of the intradiscal tissue, but only 12 $(10.23 \%)$ had posterior disc height of less than 3 $\mathrm{mm}$. Calculating the expected counts and comparing them to actual counts under null hypothesis that no association existed between the presence of an intraoperatively vacuum disc and reduced posterior disc height of less than $3 \mathrm{~mm}$ under even distribution clearly showed at a statistically significant level $(P<.001)$ that the null hypothesis had to be rejected.

A total of 124 of the 200 surgical patients $(62 \%)$ were deemed to have a vacuum disc on intraoperative probing using the "inside-out" technique. Videoendoscopic classification of the type of disc degeneration is listed in Table 8. Longitudinal fissuring of the intervertebral disc was the most common finding in 77 of these 124 patients $(62.1 \%)$. Cavitation with delamination was the second most common observation (21 patients). Cross-tabulating these findings versus outcomes show that fair outcomes were in a statistically significant manner $(P<.0001)$ associated with cavitation and delamination of the intervertebral disc from the end

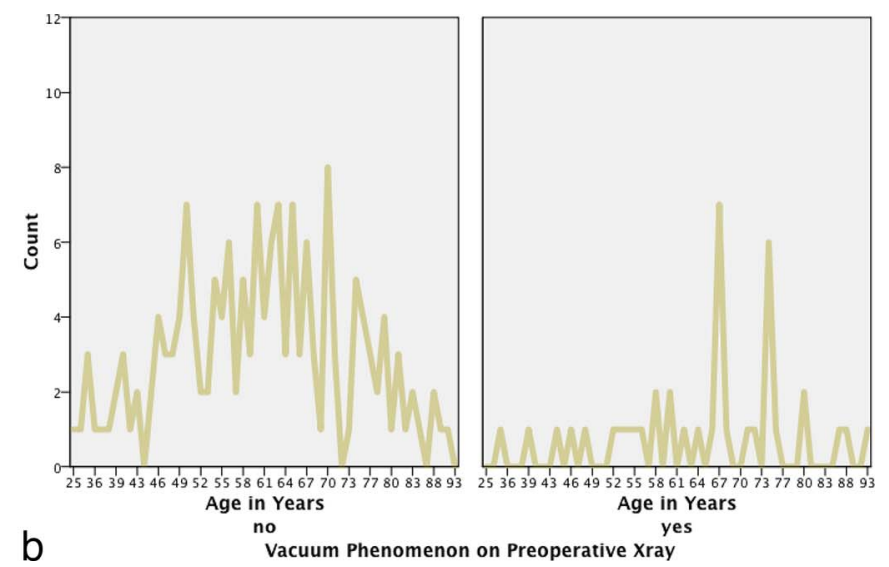

Figure 4. Top: Age distribution of patients with (right) and without (left) a vacuum phenomenon noted on preoperative x-ray (X-Ray Positive). Bottom: Age distribution of patients with (right) and without (left) intraoperatively visualized vacuum disc. 
Table 6. Outcome $\times$ Disc Height $\times$ Intraoperative Hollow Disc crosstabulation: intraoperatively visualized vacuum disc by posterior disc height versus outcome $(\mathrm{N}=200)$.

\begin{tabular}{|c|c|c|c|}
\hline \multirow{2}{*}{$\begin{array}{l}\text { Intraoperative Hollow } \\
\text { Disc and Outcome }\end{array}$} & \multicolumn{2}{|c|}{ Disc Height } & \multirow[b]{2}{*}{ Total } \\
\hline & $<\mathbf{3} \mathbf{m m}$ & $>3 \mathbf{m m}$ & \\
\hline \multicolumn{4}{|l|}{ No } \\
\hline \multicolumn{4}{|l|}{ Excellent } \\
\hline Count & & 40 & 40 \\
\hline Expected count & & 40 & 40 \\
\hline \multicolumn{4}{|l|}{ Good } \\
\hline Count & & 36 & 36 \\
\hline Expected count & & 36 & 36 \\
\hline \multicolumn{4}{|l|}{ Total } \\
\hline Count & & 76 & 76 \\
\hline Expected count & & 76 & 76 \\
\hline \multicolumn{4}{|l|}{ Yes } \\
\hline \multicolumn{4}{|l|}{ Excellent } \\
\hline Count & 2 & 6 & 8 \\
\hline Expected count & 3.2 & 4.8 & 8.0 \\
\hline \multicolumn{4}{|l|}{ Fair } \\
\hline Count & 33 & 0 & 33 \\
\hline Expected count & 13 & 20 & 33 \\
\hline \multicolumn{4}{|l|}{ Good } \\
\hline Count & 12 & 69 & 81 \\
\hline Expected count & 32 & 49 & 81 \\
\hline \multicolumn{4}{|l|}{ Poor } \\
\hline Count & 2 & 0 & 2 \\
\hline Expected count & 0.8 & 1.2 & 2.0 \\
\hline \multicolumn{4}{|l|}{ Total } \\
\hline Count & 49 & 75 & 124 \\
\hline Expected count & 49 & 75 & 124 \\
\hline \multicolumn{4}{|l|}{ Total } \\
\hline \multicolumn{4}{|l|}{ Excellent } \\
\hline Count & 2 & 46 & 48 \\
\hline Expected count & 11.8 & 36.2 & 48.0 \\
\hline \multicolumn{4}{|l|}{ Fair } \\
\hline Count & 33 & 0 & 33 \\
\hline Expected count & 8.1 & 24.9 & 33.0 \\
\hline \multicolumn{4}{|l|}{ Good } \\
\hline Count & 12 & 105 & 117 \\
\hline Expected count & 28.7 & 88.3 & 117.0 \\
\hline \multicolumn{4}{|l|}{ Poor } \\
\hline Count & 2 & 0 & 2 \\
\hline Expected count & 0.5 & 1.5 & 2.0 \\
\hline \multicolumn{4}{|l|}{ Total } \\
\hline Count & 49 & 151 & 200 \\
\hline Expected count & 49 & 151 & 200 \\
\hline
\end{tabular}

Table 7. Statistical analyses for intraoperatively visualized vacuum disc by posterior disc height versus outcome $(\mathrm{N}=200)$.

\begin{tabular}{lccc}
\hline $\begin{array}{l}\text { Intraoperative } \\
\text { Hollow Disc }\end{array}$ & Value & df & $\begin{array}{c}\text { Asymptotic } \\
\text { Significance } \\
\text { (2-Sided) }\end{array}$ \\
\hline No & & & \\
$\quad$ Pearson $\chi^{2}$ & _ $^{\mathrm{a}}$ & & \\
$\quad$ No. of valid cases & 76 & & \\
Yes & $74.955^{\mathrm{b}}$ & 3 & .000 \\
$\quad$ Pearson $\chi^{2}$ & 89.455 & 3 & .000 \\
$\quad$ Likelihood ratio & 124 & & \\
$\quad$ No. of valid cases & $131.418^{\mathrm{c}}$ & 3 & .000 \\
Total & 128.703 & 3 & .000 \\
$\quad$ Pearson $\chi^{2}$ & 200 & & \\
$\quad$ Likelihood ratio & & \\
$\quad$ No. of valid cases & & & \\
\hline
\end{tabular}

${ }^{\mathrm{a}}$ No statistics are computed because disc height is a constant.

${ }^{\mathrm{b}} 4$ cells $(50 \%)$ have expected count less than 5 . The minimum expected count is 0.79 .

${ }^{c} 2$ cells $(25 \%)$ have expected count less than 5 . The minimum expected count is 0.49 .
Table 8. Cross-tabulation of directly visualized type of disc degeneration vs manual intradiscal integrity probing $(\mathrm{N}=200)$.

\begin{tabular}{lcrr}
\hline & \multicolumn{2}{c}{ Intraop Hollow Disc } & \\
\cline { 2 - 3 } $\begin{array}{l}\text { Intradiscal Directly Visualized } \\
\text { Type of Disc Degeneration }\end{array}$ & No & Yes & Total \\
\hline Cavity & 0 & 5 & 5 \\
Cavity and delamination & 0 & 21 & 21 \\
Fissuring & 0 & 77 & 77 \\
Fissuring and cavity & 0 & 9 & 9 \\
Fissuring and Delamination & 0 & 12 & 12 \\
Stable nucleus & 76 & 0 & 76 \\
Total & 76 & 124 & 200 \\
\hline
\end{tabular}

plates. Other common combination findings of intradiscally visualized types of disc degeneration associated with fair outcomes included "Fissuring \& Cavity" (6 of 33 patients), and "Fissuring \& Delamination" (5 of 33 patients). However, another 68 patients with fissuring demonstrated good clinical outcomes (Tables 9 and 10). Cross-tabulation of type of intradiscally visualized type of disc degeneration (fissuring, cavitation, delamination) and posterior disc height $(<3 \mathrm{~mm}$, or $>3 \mathrm{~mm})$ versus clinical outcomes (excellent, good, fair, and poor) confirms that fair clinical outcomes are associated with combined "Cavitation \& Delamination" and reduced posterior disc height $(<3 \mathrm{~mm})$ of the intervertebral disc in a statistically significant manner $(P<.0001$; Tables 11 and 12). This analysis also showed that fissuring of the vacuum intervertebral disc combined with preserved posterior disc height of $3 \mathrm{~mm}$ or greater was associated within 63 of the 68 patients $(92.65 \%)$ with good outcomes $(P<.001)$.

\section{DISCUSSION}

This study shows that routine preoperative lumbar plain film studies are highly specific $(97.4 \%)$ and predictive of finding a vacuum lumbar intervertebral disc on direct "inside-out" visualization of the intradiscal space once a vacuum phenomenon is noticed. The low sensitivity of

Table 9. Cross-tabulation of type of intraoperatively visualized disc degeneration versus outcome $(\mathrm{N}=200)$.

\begin{tabular}{lcrrrrr}
\hline & \multicolumn{4}{c}{ Outcome } & \\
\cline { 2 - 5 } $\begin{array}{l}\text { Intradiscal Directly Visualized } \\
\text { Type of Disc Degeneration }\end{array}$ & Excellent & Fair & Good & Fair & Total \\
\hline Cavity & 0 & 1 & 3 & 1 & 5 \\
Cavity and delamination & 1 & 19 & 1 & 0 & 21 \\
Fissuring & 6 & 2 & 68 & 1 & 77 \\
Fissuring and cavity & 1 & 6 & 2 & 0 & 9 \\
Fissuring and delamination & 0 & 5 & 7 & 0 & 12 \\
Stable nucleus & 40 & 0 & 36 & 0 & 76 \\
Total & 48 & 33 & 117 & 2 & 200 \\
\hline
\end{tabular}


Table 10. Statistical analyses for crosstabulation of type of intraoperatively visualized disc degeneration versus outcome ( $N=200$ valid cases).

\begin{tabular}{llcc}
\hline & Value & df & $\begin{array}{c}\text { Asymptotic } \\
\text { Significance } \\
\text { (2-Sided) }\end{array}$ \\
\hline Pearson $\chi^{2}$ & $196.909^{\mathrm{a}}$ & 15 & .000 \\
Likelihood ratio & 166.773 & 15 & .000 \\
\hline
\end{tabular}

${ }^{\mathrm{a}} 14$ cells $(58.3 \%)$ have expected count less than 5 . The minimum expected count is 0.05 .

lumbar x-ray $(28.2 \%)$, on the other hand, suggests that there is a large number of patients whose lumbar $\mathrm{x}$-rays are falsely negative for vacuum phenomenon (Table 3). Although this in itself may not be surprising, the frequency of structural disruption of the nuclear tissue on the inside of the intervertebral disc established with the endoscopic "inside-out" direct visualization technique was hitherto unreported. Nearly two-thirds of patients undergoing routine lumbar transforaminal endoscopic decompression were found to have internal structural damage that allowed the surgeon to advance a $3.8-\mathrm{mm}$ diameter pituitary probe from the annular entry point on the surgical side all the way to the opposite annulus traversing the entire disc space. For the purpose of this analysis, this finding was defined as a "vacuum" disc. It implies that these types of patients would potentially suffer from vertical instability-induced dynamic foraminal and lateral recess stenosis and more mechanical

Table 11. Cross-tabulation of type of intraoperatively visualized disc degeneration versus outcome and disc height $(N=200)$.

\begin{tabular}{|c|c|c|c|c|c|}
\hline \multirow{2}{*}{$\begin{array}{l}\text { Disc Height and Intradiscally } \\
\text { Visualized Type of Disc } \\
\text { Degeneration }\end{array}$} & \multicolumn{4}{|c|}{ Outcome } & \multirow[b]{2}{*}{ Tota } \\
\hline & Excellent & Fair & Good & Poor & \\
\hline \multicolumn{6}{|l|}{$<3 \mathrm{~mm}$} \\
\hline Cavity & 0 & 1 & 1 & 1 & 3 \\
\hline Cavity and delamination & 0 & 19 & 2 & 0 & 19 \\
\hline Fissuring & 1 & 2 & 5 & 1 & 9 \\
\hline Fissuring and cavity & 1 & 6 & 1 & 0 & 8 \\
\hline Fissuring and delamination & 0 & 5 & 5 & 0 & 10 \\
\hline Total & 2 & 33 & 12 & 2 & 49 \\
\hline \multicolumn{6}{|l|}{$>3 \mathrm{~mm}$} \\
\hline Cavity & 0 & & 2 & & 2 \\
\hline Cavity and delamination & 1 & & 1 & & 2 \\
\hline Fissuring & 5 & & 63 & & 68 \\
\hline Fissuring and cavity & 0 & & 1 & & 1 \\
\hline Fissuring and delamination & 0 & & 2 & & 2 \\
\hline Stable nucleus & 40 & & 36 & & 76 \\
\hline Total & 46 & & 105 & & 151 \\
\hline \multicolumn{6}{|l|}{ Total } \\
\hline Cavity & 0 & 1 & 3 & 1 & 5 \\
\hline Cavity and delamination & 1 & 19 & 1 & 0 & 21 \\
\hline Fissuring & 6 & 2 & 68 & 1 & 77 \\
\hline Fissuring and cavity & 1 & 6 & 2 & 0 & 9 \\
\hline Fissuring and delamination & 0 & 5 & 7 & 0 & 12 \\
\hline Stable nucleus & 40 & 0 & 36 & 0 & 76 \\
\hline Total & 48 & 33 & 117 & 2 & 200 \\
\hline
\end{tabular}

Table 12. Statistical analyses for cross-tabulation of type of intraoperatively visualized disc degeneration versus outcome and disc height.

\begin{tabular}{llcc}
\hline Disc Height & Value & df & $\begin{array}{r}\text { Asymptotic } \\
\text { Significance } \\
\text { (2-Sided) }\end{array}$ \\
\hline$<3 \mathrm{~mm}$ & & 12 & .002 \\
$\quad$ Pearson $\chi^{2}$ & $30.857^{\mathrm{a}}$ & 12 & .001 \\
$\quad$ Likelihood ratio & 32.538 & & \\
$\quad$ No. of valid cases & 49 & 5 & $<.0001$ \\
$>3 \mathrm{~mm}$ & & 5 & $<.0001$ \\
Pearson $\chi^{2}$ & $37.327^{\mathrm{b}}$ & & $<.0001$ \\
Likelihood ratio & 42.008 & & $<.0001$ \\
$\quad$ No. of valid cases & 151 & 15 & \\
Total & $196.909^{\mathrm{c}}$ & 15 & \\
$\quad$ Pearson $\chi^{2}$ & 166.773 & & \\
Likelihood ratio & 200 & & \\
No. of valid cases & & &
\end{tabular}

${ }^{\mathrm{a}} 16$ cells $(80 \%)$ have expected count less than 5 . The minimum expected count is 0.12 .

b8 cells $(66.7 \%)$ have expected count less than 5 . The minimum expected count is 0.30 .

${ }^{\mathrm{c}} 14$ cells $(58.3 \%)$ have expected count less than 5 . The minimum expected count is 0.05 .

back pain due to painful innervation of the end plate seen in advanced disc degeneration. ${ }^{10}$ Conceivably, less favorable clinical outcomes would be expected. This clinical question was the motivation for this investigation.

As one would expect, most patients with a vacuum phenomenon on lumbar plain film studies were between ages 65 and 77 years. In contrast, the "inside-out" inspection of the intradiscal space showed that a vacuum disc can be found much earlier in life in the absence of any x-ray findings, with the overall disease prevalence found in this study being $62 \%$. The age of patients with intraoperative direct visualization of a structurally defective vacuum disc ranged from 42 to 82 years. There was no statistically significant difference in the frequency of a vacuum disc between women and men. Nor did it matter whether the patients had a left-sided, right-sided, or bilateral approach for the transforaminal decompression (Table 2). This study showed normal age distribution and mean follow-up much longer than 24 months, with most patients having been followed up for more than 30 months (Figures 1 and 2). The most common surgical level was L4/L5, with it having been decompressed $51.5 \%$ of the time, followed by the L5/S1 level, having been operated on $19.5 \%$ of the time (Table 1).

Clinical outcomes of this study were consistent with previously reported outcome data after microdiscectomy ${ }^{71-74}$ and endoscopic transforaminal decompression (Table 2). ${ }^{74}$ Although every patient with an extruded disc herniation had excellent 
clinical outcomes using the Macnab criteria, patients with contained disc herniations (62 of 200) had excellent and good results $82.2 \%$ of the time, and patients with spinal stenosis (130 of 200) had them $81.5 \%$ of the time. Good clinical outcomes were also observed in patients with fluoroscopic vacuum disc sign and intraoperative direct visualization of it with the "inside-out" transforaminal endoscopic technique if only fissuring was found. Fair and poor outcomes were associated with a vacuum disc, reduced posterior disc height of less than $3 \mathrm{~mm}$, and advanced degenerative structural damage of the intervertebral disc (fissuring combined either with cavitation or delamination; Tables 11 and 12) with statistical significance $(P=.001)$. This suggests that the combination of these intraoperative observations of the directly visualized intradiscal pathology is a prognosticator of less favorable clinical outcomes with the transforaminal decompression procedure. Therefore, favorable clinical results can still be expected in the presence of the vacuum disc as long as the patient has preserved posterior disc height $(>3 \mathrm{~mm})$.

Ideally, an integral conclusive preoperative workup of patients suffering from sciatica-type leg and back pain would include knowledge of whether the patient does or does not have a "vacuum" vertically unstable lumbar intervertebral disc prior to formulating a sound surgical treatment plan. Because a vacuum intervertebral disc has been associated with vertical instability-induced dynamic foraminal and lateral recess stenosis, intradiscal injection of polymethylmethacrylate cement has been devised as an alternative outpatient treatment to aggressive interbody fusion procedures and has been found to be of particular value in reducing sciatica-type leg and low back pain in the elderly with medical comorbidities. ${ }^{75,76}$ The latter 2 studies by Varga et al. on large groups of patients serves as proof of concept. Although the authors are not suggesting that every patient with a vacuum disc and reduced posterior disc height observed on preoperative $\mathrm{x}$-rays is better off with a primary interbody height reconstruction fusion procedure, exactly that has been reported by Yen et al., ${ }^{77}$ who studied the effects of intradiscal vacuum phenomenon on surgical outcome of lateral interbody fusion for degenerative lumbar disease. These authors also concluded that a vacuum phenomenon on preoperative lumbar plain film studies remains grossly underreported and that its presence provides increased ability to restore disc height and segmental lordosis and is associated with better clinical outcomes. ${ }^{77}$

The low sensitivity of lumbar plain film studies in accurately diagnosing the presence of a vacuum intervertebral disc precludes them as the only preoperative study to arrive at that diagnosis. It underlines the need for additional prognosticators to identify patients who are at high risk for less favorable outcomes if treated with an endoscopic transforaminal decompression procedure alone. Therefore, further study of the role of primary interbody height restoration fusion, such as the LEW-LIF, ${ }^{52}$ in patients undergoing endoscopic transforaminal decompression needs, at a minimum, further study to arrive at more appropriate patient selection criteria aside from history and physical examination.

\section{CONCLUSION}

The sensitivity of routine lumbar preoperative plain film studies to accurately predict the presence of a vacuum intervertebral disc is low. The specificity is high, indicating that once a vacuum phenomenon is seen on lumbar x-rays it is, in fact, present and may impact clinical outcomes following an endoscopic transforaminal decompression procedure. A vacuum and collapsed disc ( $<3 \mathrm{~mm}$ posterior disc height) is associated in a highly statistically significant manner with less favorable clinical outcomes. Intradiscal cavitation and nuclear delamination from the end plates were also related to fair clinical outcomes. Further studies are required to define imaging prognosticators and patient selection criteria. The simplified objective and principal finding of this article suggests that radiographic identification of the vacuum disc phenomenon from routine x-rays may still indicate favorable outcomes with the transforaminal decompression procedure as long as the posterior disc height is preserved to a minimum of 3 $\mathrm{mm}$. This conclusion is consistent with the outcome data of the present study's coauthors J.F.R.L. and A.Y., ${ }^{16-21,78-83}$ who contributed to this article their extensive clinical experience and shared information about successful endoscopic disc decompression and foraminoplasty in patients suffering from nonspecific chronic back pain in whom the only indication for traditional open surgery would have been fusion for severe back pain. The "inside-out" technique employed herein is more than a method used to visualize the intradiscal pathology or to identify patients who need replacement of their end-stage degenerative disc 
with an intervertebral implant. It is a "targeted" method using various emerging decompression technologies and employs newly developed surgical devices and instrumentation such as flexible pituitaries, shavers, automated burrs, and visualized laser energy for intradiscal therapy, as well as decompression of the foramen, and the lateral recess. It is the platform for emerging technologies, such as the LEW-LIF. ${ }^{52}$

\section{REFERENCES}

1. Liao JC, Lu ML, Niu CC, Chen WJ, Chen LH. Surgical outcomes of degenerative lumbar spondylolisthesis with anterior vacuum disc: can the intervertebral cage overcome intradiscal vacuum phenomenon and enhance posterolateral fusion? J Orthop Sci. 2014;19(6):851-859.

2. An KC, Kong GM, Park DH, Baik JM, Youn JH, Lee WS. Comparison of posterior lumbar interbody fusion and posterolateral lumbar fusion in monosegmental vacuum phenomenon within an intervertebral disc. Asian Spine $J$. 2016;10(1):93-98.

3. Yen CP, Beckman JM, Vivas AC, Bach K, Uribe JS. Effects of intradiscal vacuum phenomenon on surgical outcome of lateral interbody fusion for degenerative lumbar disease. $J$ Neurosurg Spine. 2017;26(4):419-425.

4. Murata K, Akeda K, Takegami N, Cheng K, Masuda K, Sudo A. Morphology of intervertebral disc ruptures evaluated by vacuum phenomenon using multi-detector computed tomography: association with lumbar disc degeneration and canal stenosis. BMC Musculoskelet Disord. 2018;19(1):164.

5. Yoshiiwa T, Miyazaki M, Notani N, Ishihara T, Kawano M, Tsumura H. Analysis of the relationship between ligamentum flavum thickening and lumbar segmental instability, disc degeneration, and facet joint osteoarthritis in lumbar spinal stenosis. Asian Spine J. 2016;10(6):1132-1140.

6. Schollmeier G, Lahr-Eigen R, Lewandrowski KU. Observations on fiber-forming collagens in the anulus fibrosus. Spine (Phila Pa 1976). 2000;25(21):2736-2741.

7. Djurasovic M, Carreon LY, Crawford CH 3rd, Zook JD, Bratcher KR, Glassman SD. The influence of preoperative MRI findings on lumbar fusion clinical outcomes. Eur Spine J. 2012;21(8):1616-1623.

8. Luoma K, Vehmas T, Kerttula L, Grönblad M, Rinne E. Chronic low back pain in relation to Modic changes, bony endplate lesions, and disc degeneration in a prospective MRI study. Eur Spine J. 2016;25(9):2873-2881.

9. Fields JA, Han M, Krug R, Lotz JC. Cartilaginous end plates: quantitative MR imaging with very short echo timesorientation dependence and correlation with biochemical composition. Radiology. 2015;274(2):482-489.

10. Fields AJ, Liebenberg EC, Lotz JC. Innervation of pathologies in the lumbar vertebral endplate and intervertebral disc. Spine J. 2014;14(3):513-521.

11. Lewandrowski KU. Positive predictive value of diagnostic epidural steroid injection for successful outcome after outpatient transforaminal decompression for lumbar foraminal and lateral recess stenosis. Clin Neurol Neurosurg. 2018;173:3845.
12. Lewandrowski KU. Retrospective analysis of accuracy and positive predictive value of preoperative lumbar MRI grading after successful outcome following outpatient endoscopic decompression for lumbar foraminal and lateral recess stenosis. Clin Neurol Neurosurg. 2019;181:52.

13. Adogwa O, Parker SL, Shau DN, et al. Cost per qualityadjusted life year gained of revision neural decompression and instrumented fusion for same-level recurrent lumbar stenosis: defining the value of surgical intervention. J Neurosurg Spine. 2012;16(2):135-140.

14. O'Lynnger TM, Zuckerman SL, Morone PJ, Dewan MC, Vasquez-Castellanos RA, Cheng JS. Trends for spine surgery for the elderly: implications for access to healthcare in North America. Neurosurgery. 2015;77(suppl 4):S136-S141.

15. Lewandrowki KU. Surgical technique of endoscopic transforaminal decompression and fusion with a threaded expandable interbody fusion cage and a report of 24 cases. $J$ Spine. 2018;7(2):409.

16. Yeung AT. Lessons learned from 27 years' experience and focus operating on symptomatic conditions of the spine under local anesthesia: the role and future of endoscopic spine surgery as a "disruptive technique" for evidenced based medicine. J Spine. 2018;7(2):413.

17. Yeung AT. Delivery of spine care under health care reform in the United States. J Spine. 2017;6(2):372.

18. Yeung AT. In-vivo endoscopic visualization of pain generators in the lumbar spine. J Spine. 2017;6:385.

19. Yeung AT, Yeung CA, Salari N, Field J, Navratil J, Maio H. Lessons learned using local anesthesia for minimally invasive endoscopic spine surgery. J Spine. 2017;6:377.

20. Yeung A, Yeung CA. Endoscopic identification and treating the pain generators in the lumbar spine that escape detection by traditional imaging studies. J Spine. 2017;6:369.

21. Yeung AT. Transforaminal endoscopic decompression for painful degenerative conditions of the lumbar spine: a review of one surgeon's experience with over 10,000 cases since 1991. J Spine Neurosurg. 2017;6:2.

22. Kee JR, Smith RG, Barnes CL. Recognizing and reducing the risk of opioid misuse in orthopaedic practice. $J$ Surg Orthop Adv. 2016;25(4):238-243.

23. Cheatle MD. Facing the challenge of pain management and opioid misuse, abuse and opioid-related fatalities. Expert Rev Clin Pharmacol. 2016;9(6):751-754.

24. Hupp JR. The surgeon's roles in stemming the prescription opioid abuse epidemic. J Oral Maxillofac Surg. 2016;74(7):1291-1293.

25. Debono B, Sabatier P, Garnault V, et al. Outpatient lumbar microdiscectomy in France: from an economic imperative to a clinical standard-an observational study of 201 cases. World Neurosurg. 2017;106:891-897.

26. Hersht M, Massicotte EM, Bernstein M. Patient satisfaction with outpatient lumbar microsurgical discectomy: a qualitative study. Can J Surg. 2007;50(6):445-459.

27. Lewandrowski KU. "Outside-in" technique, clinical results, and indications with transforaminal lumbar endoscopic surgery: a retrospective study on 220 patients on applied radiographic classification of foraminal spinal stenosis. Int $J$ Spine Surg. 2014;8.

28. Shaikh S, Chung F, Imarengiaye C, Yung D, Bernstein M. Pain, nausea, vomiting and ocular complications delay 
discharge following ambulatory microdiscectomy. Can J Anaesth. 2003;50(5):514-518.

29. Yeung AT, Yeung CA. Minimally invasive techniques for the management of lumbar disc herniation. Orthop Clin North Am. 2007;38(3):363-372.

30. Tsou PM, Alan Yeung C Yeung AT. Posterolateral transforaminal selective endoscopic discectomy and thermal annuloplasty for chronic lumbar discogenic pain: a minimal access visualized intradiscal surgical procedure. Spine $J$. 2004;4(5):564-573.

31. Tsou PM, Yeung AT. Transforaminal endoscopic decompression for radiculopathy secondary to intracanal noncontained lumbar disc herniations: outcome and technique. Spine J. 2002;2(1):41-48.

32. Yeung AT, Yeung CA. Advances in endoscopic disc and spine surgery: foraminal approach. Surg Technol Int. 2003;11:255-263.

33. Lewandrowski KU. Readmissions after outpatient transforaminal decompression for lumbar foraminal and lateral recess stenosis. Int J Spine Sug. 2018;12(3):342-351.

34. Lewandrowski KU. Incidence, management, and cost of complications after transforaminal endoscopic decompression surgery for lumbar foraminal and lateral recess stenosis: a value proposition for outpatient ambulatory surgery. Int $J$ Spine Surg. 2019;13(1):53-67.

35. Yeung A, Roberts A, Zhu L, Qi L, Zhang J, Lewandrowski KU. Treatment of soft tissue and bony spinal stenosis by a visualized endoscopic transforaminal technique under local anesthesia. Neurospine. 2019;16(1):52-62.

36. Gollogly S, Yeung A. Endoscopic spine surgery: navigating the learning curve. J Spine. 2018;7(4):010.

37. Lee CH, Choi M, Ryu DS, et al. Efficacy and safety of full-endoscopic decompression via interlaminar approach for central or lateral recess spinal stenosis of the lumbar spine: a meta-analysis. Spine (Phila Pa 1976). 2018;43(24):1756-1764.

38. Sengupta DK, Herkowitz HN. Lumbar spinal stenosis: treatment strategies and indications for surgery. Orthop Clin North Am. 2003;34(2):281-295.

39. Zhou YL, Chen G, Bi DC, Chen X. Short-term clinical efficacy of percutaneous transforaminal endoscopic discectomy in treating young patients with lumbar disc herniation. J Orthop Surg Res. 2018;13(1):61.

40. Siepe CJ, Sauer D, Michael Mayer . Full endoscopic, bilateral over-the-top decompression for lumbar spinal stenosis. Eur Spine J. 2018;27(suppl 4):563-565.

41. Gore S, Yeung A. The "inside out" transforaminal technique to treat lumbar spinal pain in an awake and aware patient under local anesthesia: results and a review of the literature. Int J Spine Surg. 2014;8.

42. Yeung AT. The evolution and advancement of endoscopic foraminal surgery: one surgeon's experience incorporating adjunctive technologies. SAS J. 2007;1(3):108-117.

43. Boos N, Rieder R, Schade V, Spratt KF, Semmer N, Aebi M. The 1995 Volvo Award in clinical sciences. The diagnostic accuracy of magnetic resonance imaging, work perception, and psychosocial factors in identifying symptomatic disc herniations. Spine (Phila Pa 1976). 1995;20(24):2613-2625.

44. Buirski G, Silberstein M. The symptomatic lumbar disc in patients with low-back pain. Magnetic resonance imaging appearances in both a symptomatic and control population. Spine (Phila Pa 1976). 19931;18(13):1808-1811.
45. Modic MT, Ross JS. Lumbar degenerative disk disease. Radiology. 2007;245(1):43-61.

46. Jensen MC, Brant-Zawadzki MN, Obuchowski N, Modic MT, Malkasian D, Ross JS. Magnetic resonance imaging of the lumbar spine in people without back pain. $N$ Engl J Med. 1994;331(2):69-73.

47. Boden SD, Davis DO, Dina TS, Patronas NJ, Wiesel SW. Abnormal magnetic resonance scans of the lumbar spine in asymptomatic subjects: a prospective investigation. $J$ Bone Joint Surg Am. 1990;72(3):403-408.

48. Beattie PF, Meyers SP, Stratford P, Millard RW, Hollenberg GM. Associations between patient report of symptoms and anatomic impairment visible on lumbar magnetic resonance imaging. Spine (Phila Pa 1976). 2000;25(7):819-828.

49. Dutta S, Bhave A, Patil S. Correlation of 1.5 Tesla magnetic resonance imaging with clinical and intraoperative findings for lumbar disc herniation. Asian Spine $J$. 2016;10(6):1115-1121.

50. Crosby CG, Even JL, Song Y, Block JJ, Devin CJ. Diagnostic abilities of magnetic resonance imaging in traumatic injury to the posterior ligamentous complex: the effect of years in training. Spine J. 2011;11(8):747-753.

51. Pfirrmann CW, Metzdorf A, Zanetti M, Hodler J, Boos N. Magnetic resonance classification of lumbar intervertebral disc degeneration. Spine (Phila Pa 1976). 2001;26(17):18731878 .

52. Lewandrowski KU, Ransom NA, Ramírez León RF, Yeung A. The concept for a standalone lordotic endoscopic wedge lumbar interbody fusion: the LEW-LIF. Neurospine. 2019;16(1):1-14.

53. Botwin KP, Gruber RD, Bouchlas CG, et al. Fluoroscopically guided lumbar transformational epidural steroid injections in degenerative lumbar stenosis: an outcome study. Am J Phys Med Rehabil. 2002;81(12):898-905.

54. el-Khoury GY, Ehara S, Weinstein JN, Montgomery WJ, Kathol MH. Epidural steroid injection: a procedure ideally performed with fluoroscopic control. Radiology. 1988;168(2):554-557.

55. Bogduk N, Aprill C, Derby R. Epidural spinal injections. In: White AH, Schollerman J, eds. Spinal Care: Diagnosis and Treatment. Maryland Heights, MD: Mosby; 1995:322-343.

56. Huskisson EC, Jones J, Scott PJ. Application of visualanalogue scales to the measurement of functional capacity. Rheumatol Rehabil. 1976;15(3):185-187.

57. Thomas RJ, McEwen J, Asbury AJ. The Glasgow Pain Questionnaire: a new generic measure of pain; development and testing. Int J Epidemiol. 1996;25(5):1060-1067.

58. Lee IS, Kim SH, Lee JW, et al. Comparison of the temporary diagnostic relief of transforaminal epidural steroid injection approaches: conventional versus posterolateral technique. AJNR Am J Neuroradiol. 2007;28(2):204-208.

59. Macnab I. Negative disc exploration: an analysis of the causes of nerve-root involvement in sixty-eight patients. $J$ Bone Joint Surg Am. 1971;53(5):891-903.

60. Murata K, Akeda K, Takegami N, Cheng K, Masuda K, Sudo A. Morphology of intervertebral disc ruptures evaluated by vacuum phenomenon using multi-detector computed tomography: association with lumbar disc degeneration and canal stenosis. BMC Musculoskelet Disord. 2018;19(1):164.

61. Lee CK, Rauschning W, Glenn W. Lateral lumbar spinal 
canal stenosis: classification, pathologic anatomy, and surgical decompression. Spine (Phila Pa 1976). 1988;13(3):313-320.

62. Lee S, Kim SK, Lee SH, et al. Percutaneous endoscopic lumbar discectomy for migrated disc herniation: classification of disc migration and surgical approaches. Eur Spine J. 2007; 16(3):431-437.

63. Hasegawa T, An HS, Haughton VM, Nowicki BH. Lumbar foraminal stenosis: critical heights of the intervertebral discs and foramina: a cryomicrotome study in cadavera. $J$ Bone Joint Surg Am. 1995;77(1):32-38.

64. Lee S, Lee JW, Yeom JS, et al. A practical MRI grading system for lumbar foraminal stenosis. AJR Am J Roentgenol. 2010;194(4):1095-1098.

65. Hoogland T, Schubert M, Miklitz B, Ramirez A. Transforaminal posterolateral endoscopic discectomy with or without the combination of a low-dose chymopapain: a prospective randomized study in 280 consecutive cases. Spine (Phila Pa 1976). 2006;31(24):E890-E897.

66. Schubert M, Hoogland T. Endoscopic transforaminal nucleotomy with foraminoplasty for lumbar disk herniation. Oper Orthop Traumatol. 2005;17(6):641-661.

67. Kambin P, Casey K, O’Brien E, Zhou L. Transforaminal arthroscopic decompression of lateral recess stenosis. $J$ Neurosurg. 1996;84(3):462-467.

68. Kambin P, O'Brien E, Zhou L, Schaffer JL. Arthroscopic microdiscectomy and selective fragmentectomy. Clin Orthop Relat Res. 1998;(347):150-167.

69. Altman DG, Machin D, Bryant TN, Gardner MJ, eds. Statistics with Confidence: Confidence Intervals and Statistical Guidelines. 2nd ed. Hoboken, NJ: BMJ Books; 2000.

70. Mercaldo ND, Lau KF, Zhou XH. Confidence intervals for predictive values with an emphasis to case-control studies. Stat Med. 2007;26(10):2170-2183.

71. Sigmundsson FG, Kang XP, Jönsson B, Strömqvist B. Correlation between disability and MRI findings in lumbar spinal stenosis: a prospective study of 109 patients operated on by decompression. Acta Orthop. 2011;82(2):204-210.

72. Asch HL, Lewis PJ, Moreland DB, et al. Prospective multiple outcomes study of outpatient lumbar microdiscectomy: should 75 to $80 \%$ success rates be the norm? J Neurosurg. 2002;96(1 suppl):34-44.

73. Kim MJ, Lee SH, Jung ES, et al. Targeted percutaneous transforaminal endoscopic diskectomy in 295 patients: comparison with results of microscopic diskectomy. Surg Neurol. 2007;68(6):623-631.

74. Ahn Y, Lee SH, Park WM, Lee HY, Shin SW, Kang HY. Percutaneous endoscopic lumbar discectomy for recurrent disc herniation: surgical technique, outcome, and prognostic factors of 43 consecutive cases. Spine (Phila Pa 1976). 2004;29(16):E326-E332.

75. Varga PP, Jakab G, Bors IB, Lazary A, Szövérfi Z. Experiences with PMMA cement as a stand-alone intervertebral spacer: percutaneous cement discoplasty in the case of vacuum phenomenon within lumbar intervertebral discs. Orthopade. 2015;44(suppl 1):S1-S7.

76. Varga PP, Jakab G, Bors IB, Lazary A, Szövérfi Z. Experiences with PMMA cement as a stand-alone intervertebral spacer: percutaneous cement discoplasty in the case of vacuum phenomenon within lumbar intervertebral discs. Orthopade. 2015;44(2):124-131.

77. Yen CP, Beckman JM, Vivas AC, Bach K, Uribe JS, Effects of intradiscal vacuum phenomenon on surgical outcome of lateral interbody fusion for degenerative lumbar disease. $J$ Neurosurg Spine. 2017;26(4):419-425.

78. Yeung AT, Roberts A, Shin P, Rivers E, Paterson A. Suggestions for a practical and progressive approach to endoscopic spine surgery training and privileges. $J$ Spine. 2018;7(2):414.

79. Yeung AT. Robotics in the MIS Spine surgery arena: a new role to advance the adoption of endoscopic surgery as the least invasive spine surgery procedure. J Spine. 2017;6:374.

80. Yeung AT. Moving away from fusion by treating the pain generator: the secrets of an endoscopic master. $J$ Spine. 2015;4:e121.

81. Yeung AT. The role and future of endoscopic spine surgery. ContROL. 2017;1:0001.

82. Yeung AT. The Yeung percutaneous endoscopic lumbar decompressive technique. ContROL. 2017;1:0001.

83. Yeung AT. Intradiscal therapy and transforaminal endoscopic decompression: opportunities and challenges for the future. J Neurol Disord. 2016;4:303.

Disclosures and COI: The first author has no direct (employment, stock ownership, grants, patents) or indirect conflicts of interest (honoraria, consultancies to sponsoring organizations, mutual fund ownership, paid expert testimony).

Corresponding Author: Kai-Uwe Lewandrowski, MD, Center for Advanced Spine Care of Southern Arizona, 4787 E Camp Lowell Dr, Tucson, AZ 85712. Phone: (520) 204-1445; Fax: (520) 407-6740; Email: info@southerarizonaspine. com.

Published 31 October 2019

This manuscript is generously published free of charge by ISASS, the International Society for the Advancement of Spine Surgery. Copyright (c) 2019 ISASS. To see more or order reprints or permissions, see http://ijssurgery.com. 